\title{
Faulty scientific paper has damaged all sides
}

Friday Analysis Timberbiz

Australasian Timber

Australian Forests \& Timber News

04 September 2020

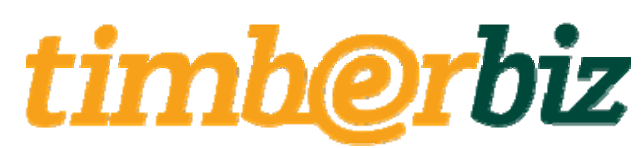

https://www.timberbiz.com.au/friday-analysis-faulty-scientific-paper-has-damaged-all-sides/ 


\title{
Australasian Timber Construction Forum is now LIVE Click here to read in full!
}

\author{
Australasian Timber $\mid$ Australian Forests \& Timber News
}

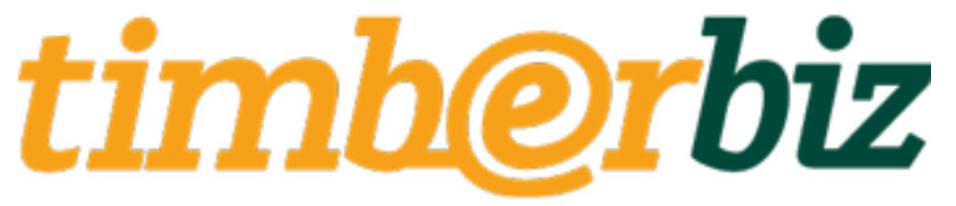

\begin{tabular}{l|l|l|l|l|l} 
Home & About & Directory » & Publications & Timber Jobs & Advertise
\end{tabular}

Search Timberbiz

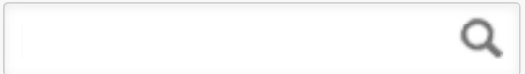

Subscribe to the FREE

enewsletter, Daily Timber

News, for current national and international timber industry news.

Daily Timber News archives

Trade and Services Directory

Publications

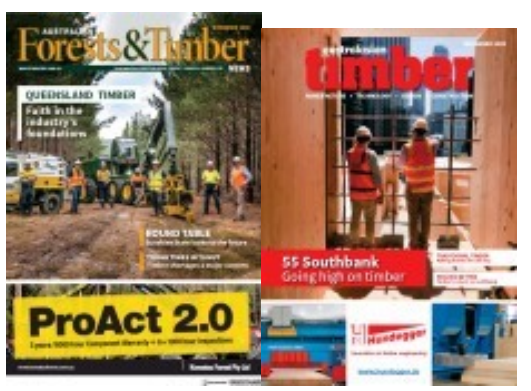

\section{Friday analysis: faulty scientific paper has damage}

04 September 2020

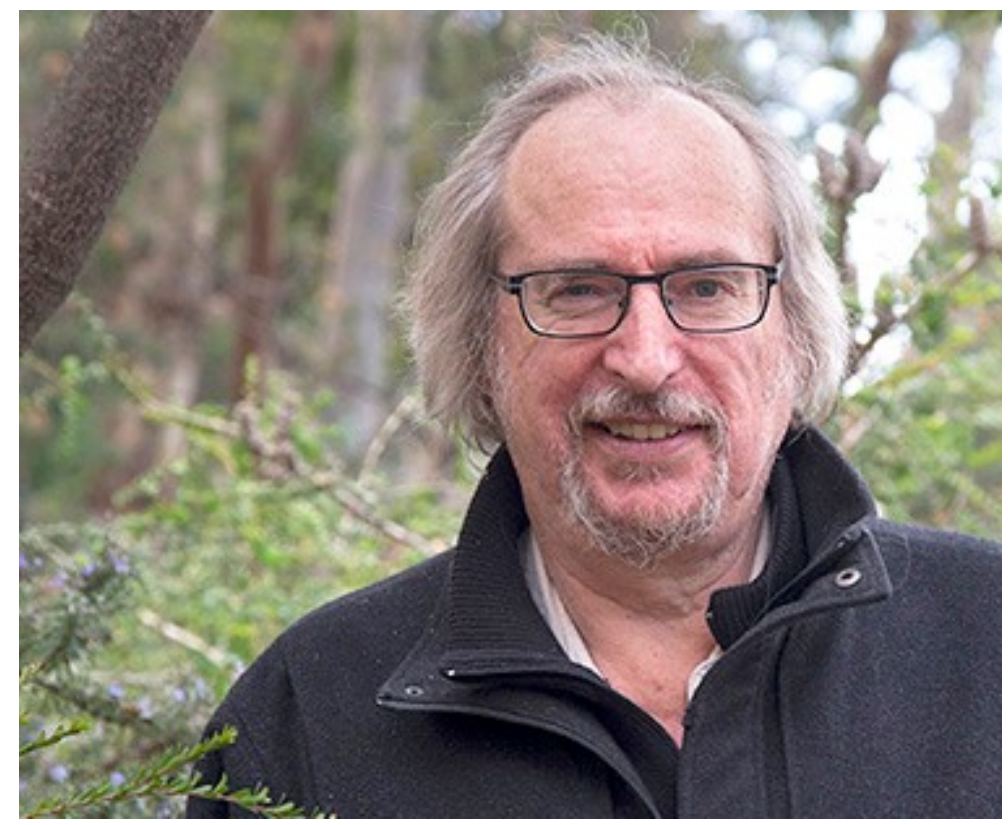

Professor James Kirkpatrick

So, a peer-reviewed scientific paper, written by Professor Jar Kirkpatrick, Suyanti Winoto-Lewin and Jenny Sanger from th of Tasmania's Discipline of Geography and Spatial Sciences, retracted from the MDPI journal Fire. The journal has apolos readers. Source: Bruce Mitchell

What does that mean to have an academic peer-reviewed $p$ : retracted by the publisher? 


\section{Recent Jobs}

No job listings found.
In academic publishing, the goal of peer review is to assess quality of articles submitted for publication in a scholarly jo Before an article is deemed appropriate to be published in a reviewed journal, it must undergo the following process:

- The author of the article must submit it to the journal $\epsilon$ forwards the article to experts in the field. Because the specialize in the same scholarly area as the author, the! considered the author's peers (hence "peer review").

- These impartial reviewers are charged with carefully el the quality of the submitted manuscript.

- The peer reviewers check the manuscript for accuracy a the validity of the research methodology and procedure

- If appropriate, they suggest revisions. If they find the ar lacking in scholarly validity and rigor, they reject it.

Because a peer-reviewed journal will not publish articles th meet the standards established for a given discipline, peer-r articles that are accepted for publication exemplify the best practices in a field.

When a retraction is applied to academic or scholarly publis indicates that an article was withdrawn from the publicatio appeared after it was published. A retraction is issued thro decision made by the publication's editorial board.

In a major paper on the subject published by the London Sc Economics, Quan-Hoang Vuong - the Director of Centre for Interdisciplinary Social Research at Phenikaa University, Har - said that "no editorial practice in academia can affect an c reputation as much as a retraction".

"The stigma is rooted in the fear of every researcher that a $r$ article ... is like a scar seared into the public profile of an au wrote.

It is quite rightly pointed out that while withdrawing papers contain errors or misconduct, helps to keep the literature $h \epsilon$ researchers, want to avoid retractions at all costs.

Quan-Hoang Vuong points out that retracted papers, no mat undesirable they are, poke right at the heart of scholarly pu

Scientists are humans, and humans are fallible, he says. 
"It is unavoidable that ... research has its limitations and ma retracted under certain circumstances," he says.

"When a retraction happens, scientists and editors/publishe should cooperate to make the information as detailed and $\mathrm{t}$. as possible."

But what of the damage that may be done should a paper retracted - be used to mount an argument for a certain acti the entire industry?

And what of the damage when the retracted paper is used $b$ academics involved as the basis of opinion pieces in major metropolitan and country newspapers to attack other contrc peer-reviewed papers?

The Greens have used the now retracted paper as the basis campaign against the native timber industry.

And the paper did form part of the platform of an opinion al Professor Kirkpatrick published in The Age and Sydney Morr newspapers in May.

Following this Dr Zylstra and the other scientists, but not Pr Kirkpatrick, published a letter to the editor reiterating these was widely published in Tasmanian and Victorian country n In June, an article by Professor Kirkpatrick strongly attacked reviewed paper on the role of timber harvesting and fire led Attiwill, a retired Associate Professor from the School of Bot Melbourne University.

The journal Fire has been applauded for its decisive and hor action, and Sanger and Winoto-Lewin condemned for their $c$ research by a growing list of stakeholders.

This list includes the Institute of Foresters Australia, the Ass Minister for Agriculture and Water Resources Senator Jonno the Tasmanian Minister for Natural Resources Guy Barnett a Tasmanian Shadow Minister for Resources Shane Broad. 
And Professor Attiwill. He, the Institute of Foresters Australi Barnett, want an apology.

"I've never had that personal level of attack in public," Prof, He said that to find that attack was based on a now retracte "deeply troubling".

The silence has, so far, been negligible.

\section{Social Share}

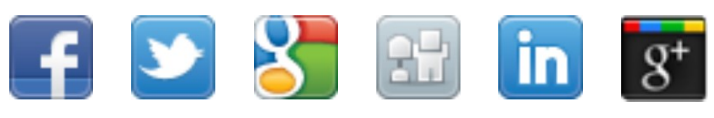

Daily Timber News

\section{Association News}

Australian Forestry News

Events

\section{Features}

General Industry News

Health \& Safety

New Zealand Forestry News

Overseas Forestry News

Products

Timber News

\section{Subscribe to DTN}

Subscribe to the Daily Timber News

* indicates required

\section{Email Address *}

\section{First Name}

\section{Last Name}

\section{Subscribe}




\section{References}

Winoto-Lewin, S., Sanger, J., \& Kirkpatrick, J. (2020). Retraction: Winoto-Lewin, S. and Sanger, J. et al. Propensities of Old Growth, Mature and Regrowth Wet Eucalypt Forest, and Eucalyptus Nitens Plantation, to Burn during Wildfire and Suffer Fire-Induced Crown Death. Fire 2020, 3, 13. Fire, 3(3), 47.

Vuong, Q. H. (2020). Retractions: the good, the bad, and the ugly. LSE Impact of Social Sciences (Feb 20, 2020). Available from:

https://blogs.Ise.ac.uk/impactofsocialsciences/2020/02/20/retractions-the-good-the-badand-the-ugly-what-researchers-stand-to-gain-from-taking-more-care-to-understand-errors-inthe-scientific-record/

Vuong, Q. H. (2020). Reform retractions to make them more transparent. Nature, 582(7811), 149. 